\title{
GLOMUS TUMOR IN FLOOR OF MOUTH: A CASE REPORT
}

Kaustuv Das Biswas ${ }^{1}$, Arya Sen², Goutam Guha ${ }^{3}$, Saibal Misra ${ }^{4}$, Ramanuj Sinha ${ }^{5}$

\section{HOW TO CITE THIS ARTICLE:}

Kaustuv Das Biswas, Arya Sen, Goutam Guha, Saibal Misra, Ramanuj Sinha. "Glomus Tumor in Floor of Mouth: A Case Report". Journal of Evolution of Medical and Dental Sciences 2014; Vol. 3, Issue 22, June 02;

Page: 6036-6042, DOI: $10.14260 /$ jemds/2014/2701

ABSTRACT: 'Glomus' has been defined as a small body surrounded by many fibres, consisting of an anastomoses between fine arterioles and veins. ${ }^{1}$ A glomus tumor or glomangioma is a benign neoplasm originating from modified smooth muscle cells of the vascular glomus ${ }^{2}$ and possibly from other types of arteriovenous anastomoses. ${ }^{3,4}$ It occurs most frequently in the dermis and subcutaneous tissues in subungual areas of fingers. ${ }^{4}$ Unusual sites include stomach, vagina, heart, mediastinum, uterus, penis, bone, lung, trachea, temporomandibular meniscus and eyelid. ${ }^{5}$ Solitary glomangioma seen most frequently on extremities whereas multiple lesions on face can occur as a part of hereditary syndrome. 6 Glomangioma of the head and/or neck are extremely rare, with an incidence of $0.6 \% .^{7}$ English literature review shows about thirty one cases of glomus tumor affecting different subsites of head and neck regions, but none showing isolated involvement floor of mouth. Here we present a rare case of involvement of floor of mouth by locally aggressive glomus tumor, the first and only case documented to date of glomus tumor in this location as far as our knowledge.

KEYWORDS: glomus tumor, floor of mouth.

CASE REPORT: A 38 years old male patient presented to the outpatient department of our institution with sudden onset painless swelling in floor of mouth with occasional episodes of bleeding from mouth for three weeks. The mass pushed up the tongue upwards and backwards causing difficulty in swallowing and speech. (Figure 1) The patient used to smoke about four cigarettes per day for about last ten years. There was no similar disorder in the past neither was there any family history. He suffered from jaundice in childhood and was reactive for hepatitis B surface antigen.

Computerised tomographic(CT) scan was performed which showed heterogeneous soft tissue mass occupying floor of mouth, $6 \mathrm{~cm}$ antero-posteriorly, $5 \mathrm{~cm}$ latero-laterally and $4 \mathrm{~cm}$ in vertical size extending anteriorly below the level of alveolus \& upto level of epiglottis as seen in parasagittal reformatted CT scan (figure 2) with no involvement of adjacent bone.

The lesion occupied floor of mouth, being centrally placed displacing the tongue upwards and backwards. (Figure 3) There was no infiltration into adjacent soft tissue spaces and muscles which were only displaced by the mass. CT scan revealed that there was no plane of cleavage between the mass \& upper part of mandible but on lower part there was a plane of cleavage between the mass \& the mandible. (Figure 4) Orthopantomography (OPG) revealed no lytic lesion in the adjacent part of mandible nor any pathological fracture.

A punch biopsy was taken from the intraoral lesion to confirm the tissue diagnosis. This led to massive swelling of the large intra-oral mass due to hematoma formation, pushing the tongue upwards \& backwards further into the oral cavity (Figure 5) causing respiratory distress for which tracheostomy was performed \& the hematoma was drained at the same sitting. The histopathology report came as bits of necrotic tissue with monomorphic round eosinophilic cells with few vascular spaces. A provisional diagnosis of glomus tumor was made and surgical excision was planned. In neck 
extended and mouth open position mandible was split horizontally one premolar to the other along the line of marginal splitting and the capsule of the tumor was identified and dissection was continued along a plane outside the capsule. (Figure 6) Lower down as the dissection became difficult, to get adequate space, mandible was again split vertically at the midline and mandible swinging was done. (Figure 7) Enough space was thus obtained to remove the tumor from floor of the mouth completely and clearance of adjacent tissue spaces under general anesthesia.

The tumor mass was removed along with teeth premolar to premolar. (Figure 8) The postoperative period was uneventful \& there is no recurrence till date. (Figure 9) The resected mass was irregular, grey-tan to brown colored soft tissue, measuring $7.5 \times 6.5 \times 5.5 \mathrm{~cm}$. On sectioning cut surface was spongy and exuded blood.

Histopathology report on routine haematoxylin and eosin stain came as thin intact fibrous capsule surrounding the tumor composed of varying population of glomus cells (monotonous round cells with pale eosinophilic cytoplasm with well-defined cell borders with occasional spindle shaped cells and mast cells; large central round or oval punched out chromatin, uniform nucleus and scanty cytoplasm) with tortuous vascular spaces containing blood and lined with endothelium scattered between the tumor cells.

The tumor cells were epithelioid in appearance or resembling smooth muscle cells arranged in perivascular distribution with focal myxoid changes of stroma and some areas of hyaline changes, features consistent with glomus tumor. (figure 10) The resected specimen of the mass was subjected to thorough histopathological examination by special stains like periodic acid-Schiff (PAS), silver impregnation for reticulin, Bodian's stain for nerve fibres and toluidine blue to rule out other differential diagnoses $\&$ to reach to a final conclusion.

The mass was composed of vascular spaces with scattered mast cells showing metachromatic reaction with toluidine blue stain. No reticulin formation noted on silver impregnation and no apparent extravascular tumor cell localization ruling out hemangiopericytoma. Bodian's stain was also negative for plexus of nerve fibres.

DISCUSSION: Masson in 1924 first recognized the relationship of painful tumors of digits to the normal glomus body and applied the term glomus tumor to them. ${ }^{3}$ Glomus tumor (glomangioma) develops as a small painful encapsulated nodule as a result of hamartomatous proliferation of modified smooth muscle cells ${ }^{8}$ found in the characteristic type of peripheral arteriovenous anastomosis known as the glomus. The arterial segment is thick walled, tortuous, termed as SucquetHoyer canal and the venous segment is thin walled, wide lumen draining into larger veins surrounding glomus. ${ }^{5}$ The glomus tumor is rare in mouth. 5,8

There is no age and sex predilection noted in literature. According to Tokiba et al ${ }^{9}$ until 1990, only 16 cases of oral or facial glomus tumors have been published in the literature, of which 4 were gingival lesions, 4 were in palate, 2 lingual lesions, 2 jugal mucosal lesions, 1 tumor in preauricular region and 2 were in lips. Six cases involving intranasal subsites were reported by Potter et al. ${ }^{10}$ One lesion in parotid region, ${ }^{11}$ one in tonsillar fossa, ${ }^{12}$ one in jugal mucosa, ${ }^{7}$ and four cases in the lips ${ }^{13-15}$, 5 have been reported.

Asymptomatic cases of lingual glomus tumor were reported by Tajima et al and Sato et al where excision under local anesthesia was performed without any recurrence. Quesada $\mathrm{R}$ et al ${ }^{2}$ described aggressive glomus tumor of tongue with local recurrence which is usually infrequent. 
Surgical removal was the treatment modality of choice in majority of the published cases of glomus tumors with complete excision resulted in resolution of symptoms. Masson in the first histologic description depicted three histologic patterns-i) angiomatous areas- most common, ii) solid areas comprising of cellular areas of smooth muscle cells and epithelioid cells and iii) degenerative areas with hyaline changes, edema and mucoid changes with myxoid appearance. These patterns are mixed into various proportions in different glomus tumors. ${ }^{3}$

In our case predominantly angiomatous areas with epithelioid cells and focal areas of hyaline changes were noted. Clinically and histologically glomus tumor has to be differentiated from hemangiopericytoma. Hemangiopericytoma is usually larger and not associated with pain. ${ }^{4}$ Glomus tumor outside the extremities are usually painless and so is our case. Histologically glomus tumor is less angiomtous and cytologically more pleomorphic.

Hyaline changes, myxoid degenerations and presence of mast cells also differentiates glomus tumor from hemangiopericytomas. ${ }^{4}$ Other differential diagnoses include leiomyoma, angiomyoma, hemangioma and neurilemmoma. Thorough light microscopic examination with routine and sometimes special dye is adequate to make final diagnosis of glomus tumor, e.g. Bodian's stain for nerve fibres can differentiate glomus tumor from neurilemmoma.

Our case of glomus tumor is rare in the subsite involved i.e. floor of the mouth without any involvement of the tongue and it is the first reported case of aggressive glomus tumor in this site. The mass although showed characteristic enhancing vascular nature confirming to glomus but surprisingly it showed no infiltration of adjacent tongue, muscles and soft tissue spaces nor caused any lytic lesion in the adjacent part of mandible. Due to huge size of the mass, it was treated with combined marginal mandibulectomy for better exposure enabling complete surgical removal.

CONCLUSION: Although rare, soft tissue mass in floor of mouth with repeated episodes of bleeding should arouse the suspicion of glomus tumor.

\section{REFERENCES:}

1. Medical dictionary. www.thefreedictionary.com. Last accessed on 4.4.2014.

2. Quesada R., Gonzalaz-Lagunas J. Raspall G. Aggressive glomus tumor of the tongue: Report of a case. Med Oral 2004; 9: 350-54.

3. Masson P., Le glomus neuromyo-arteriel des regions tactiles et ses tumeurs. Lyon Chirurg 1924; 21: 257-280.

4. Lever WF, Schaumburg-Lever G., Tumors of the vascular tissue. In Histopathology of the Skin. $5^{\text {th }}$ ed. Philadelphia. J. B. Lippincott Company. 1975, 38-39, 600-602.

5. Ficarra G, Merrel PW, Johnston WH, Hansen LS. Intraoral solitary glomus tumor (glomangioma): case report and literature review. Oral Surgery Oral Med and Oral Path 1986; 62: 306-311.

6. McEvoy BF, Waldman PM, Tye MJ. Multiple hamartomatous glomus tumor of the skin. Arch Dermatol 1971; 104: 188-191.

7. Savaci N, Emiroglu M, Gumren M, Gungor S. A rare case of glomus tumour: buccal localization. Br J Oral Maxillofacial Surg 1996; 34: 199-200.

8. Moody GH, Myskow M, Musgrove C. Glomus tumor of the lip: A case report and immunohistochemical study. Oral Surg Oral Med Oral Pathol 1986; 62:312. 
9. Tokiba S, Sato A, Sakamaki H. A case of glomus tumour arising in the mandibular gingiva. Jpn J Oral Maxillofacial Surg 1990; 36: 2295.

10. Potter AJ Jr, Khatit G, Peppard SB. Intranasal glomus tumor. Arch Otolaryngol 1984; 110: 755-6.

11. Sakashita H, Miyata M, Miyamoto H, Kuruyama H. Glomus tumour in the parotid region. J Oral Maxillofacial Surg 1995; 53: 830-4.

12. González-Campora R, Villar-Rodríguez JL. Glomus tumour of the oropharynx. Journal of Laryngology and Otology 1995; 109: 63-5.

13. Moody GH, Musgrave C. Glomus tumour of lip. Oral Surg Oral Med Oral Pathol 1986; 62:312.

14. Kusama K, Chu L, Kidokoro Y, Kouzo M, Uehara T, Honda M et al. Glomus tumor of the upper lip. J Nihon Univ Sch Dent 1995; 37: 97-101.

15. Sakashita H, Miyata M, Nagao K. Glomus tumor in the upper lip: A case report. Int J Oral and Maxillofacial Surg 1997; 26: 301-2.

Figure 1: Clinical photograph showing brown soft tissue mass occupying central part of floor of mouth pushing the tongue upward \& backward.

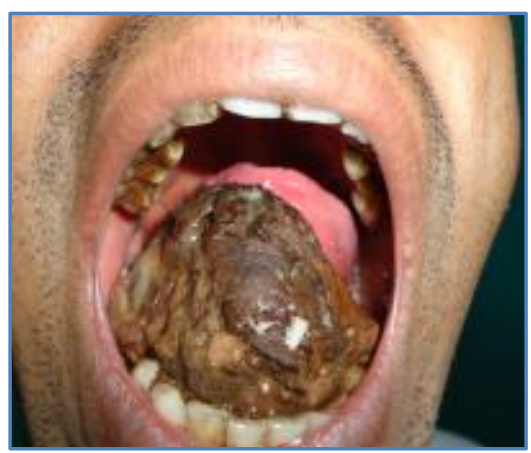

Figure 1

Figure 2: Reformatted parasagittal CT scan image showing vertical extent of floor of mouth soft tissue mass.

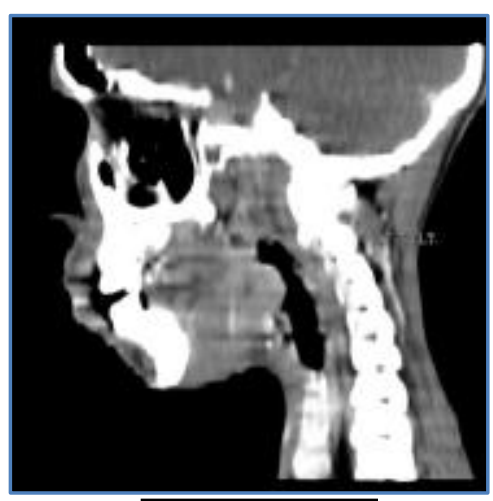

Figure 2 


\section{CASE REPORT}

Figure 3: Coronal CT scan image showing central floor of mouth soft tissue mass abutting the alveolar border of mandible.

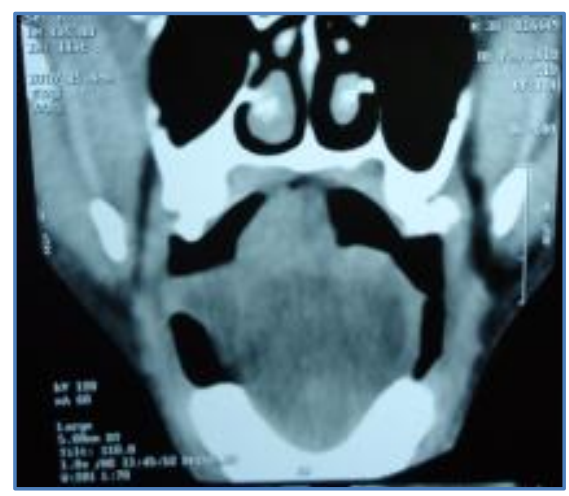

Figure 3

Figure 4: CT scan image axial cut, showing plane of cleavage between the mass \& mandible on the lower part.

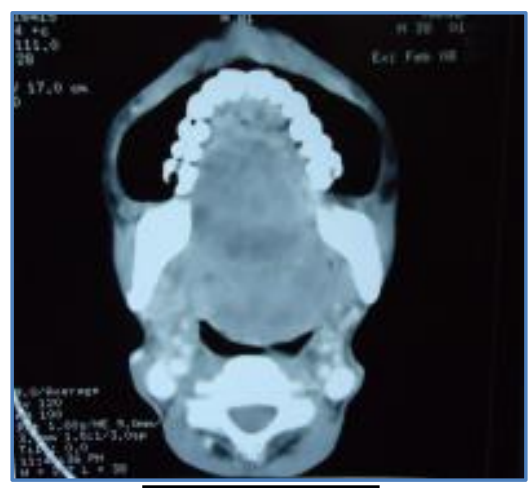

Figure 4

Figure 5: Clinical photograph showing swelling \& haematoma formation of the mass following biopsy.

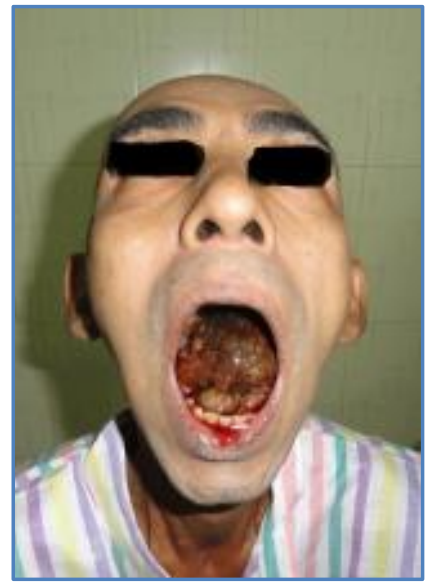

Figure 5 


\section{CASE REPORT}

Figure 6: Per-operative photograph showing marginal split of mandible premolar to premolar with extracapsular dissection being performed.

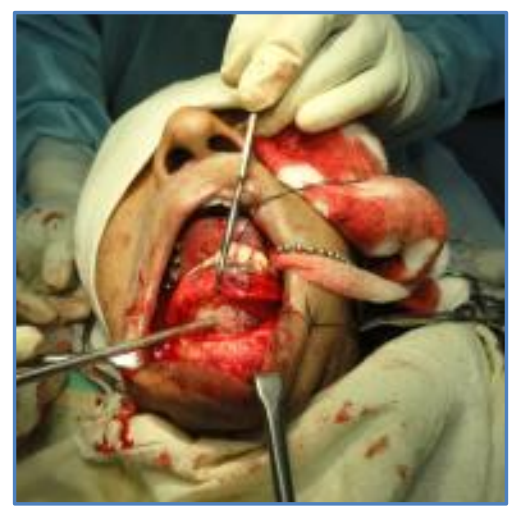

Figure 6

Figure 7: Per-operative photograph showing vertical split of the mandible (marked by arrow) with mandibular swing to reach the lower limit of the mass.

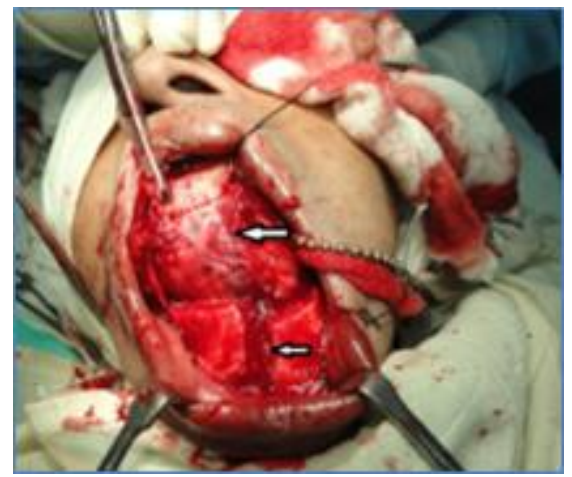

Figure 7

Figure 8: Shows the resected specimen post-operatively along with teeth premolar to premolar \& marginal part of mandible.

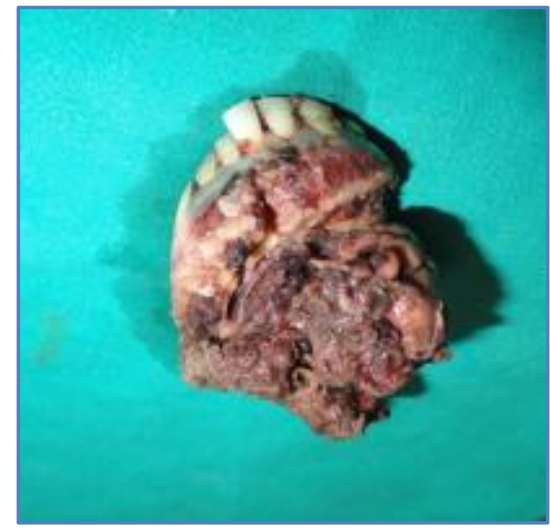

Figure 8 


\section{CASE REPORT}

Figure 9: Post-operative photograph of the patient showing healed tracheostomy scar \& no recurrence at the site of the lesion.

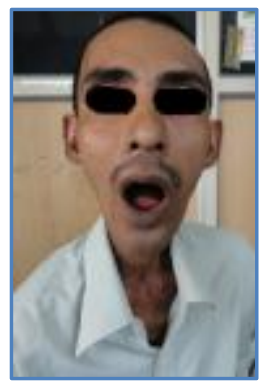

\section{Figure 9}

Figure 10: Histopathological section (H \& E, 100X) shows tumor composed of varying population of glomus cells, blood vessels \& smooth muscles. The tumor is composed of numerous monotonous, rounded glomus cells with pale eosinophilic cytoplasm with well-defined cell borders ;large central round or oval punched out uniform nucleus (black arrow).Small blood vessels are seen scattered between the tumor cells (red arrow).

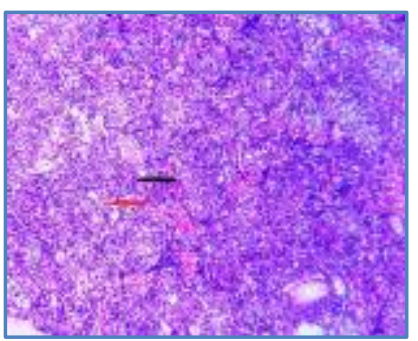

Figure 10

\section{AUTHORS:}

1. Kaustuv Das Biswas

2. Arya Sen

3. Goutam Guha

4. Saibal Misra

5. Ramanuj Sinha

\section{PARTICULARS OF CONTRIBUTORS:}

1. RMO-Cum-Clinical-Tutor, Department of Otorhinolaryngolgy, IPGMER \& SSKM Hospital, Kolkata, West Bengal, India.

2. RMO-Cum-Clinical-Tutor, Department of Immune Hematology \& Transfusion Medicine, Murshidabad Medical College, West Bengal, India.

3. Associate Professor, Department of Plastic Surgery, R. G. Kar, MCH, Kolkata, India.
4. Consultant, Department of Otorhinolaryngology Surgeon, Kolkata, West Bengal, India.

5. Professor, Department of Otorhinolaryngology, R. G. Kar, MCH, Kolkata, India.

\section{NAME ADDRESS EMAIL ID OF THE CORRESPONDING AUTHOR:}

Dr. Kaustuv Das Biswas, Avishikta 1, Flat-2B-402, 369/1, Purbachal Kalitala Road, P. O. Haltu, Kolkata-700078, West Bengal, India. Email: dr.kaustuv.82@gmail.com

Date of Submission: 10/05/2014.

Date of Peer Review: 11/05/2014.

Date of Acceptance: 17/05/2014.

Date of Publishing: 30/06/2014. 